\title{
Multielemental Analysis of Genetically Modified Food using ANAA and PIXE Techniques
}

\author{
Ilca Marli Moitinho Amaral Medeiros, Cibele Bugno Zamboni, José Agostinho Gonçalves de Medeiros, \\ Instituto de Pesquisas Energéticas e Nucleares, Caixa Postal 11049, 05422-970, São Paulo, SP, Brazil \\ Marcia de Almeida Rizzutto, Nemitala Added, and Manfredo Harri Tabacniks \\ Instituto de Física da Universidade de São Paulo, Caixa Postal 66318, 05315-970, São Paulo, SP, Brazil
}

Received on 12 August, 2005

\begin{abstract}
This paper describes the application of two techniques, ANAA and PIXE, used in the analyses of some available commercial food containing regular and genetically modified ingredients, as well as soybens cultivated with regular and genetically modified seeds (GMS). The aim of this work is determine their elemental composition to perform a comparative analysis. The elemental composition results of both types of food, obtained by the two techniques, were in agreement for all elements. Our results show the same elemental composition for all food samples but the quantitative analysis between soybeans seeds (regular and GM) suggested that the product made with GMS have higher concentration values, mainly for $\mathrm{Cl}, \mathrm{P}$ and $\mathrm{Zn}$, while for industrialized food, made with genetically modified products, a low concentration values were measured for most of the elements.
\end{abstract}

\section{INTRODUCTION}

The importance of essential elements to human health has stimulated the analysis of their occurrence in a wide variety of foodstuffs. In the early 80's, the first experiment involving the transgenic vegetables gave rise to the research on genetically modified food (GMF) production. Since then, some benefits in cellular biology as well as in agriculture were obtained. The knowledge obtained permits production of vegetables with modified quantities of lipids and proteins in seeds, virus and plagues resistance and also allows cultivation on salty soils and swamps. According to recent statistics, about $60 \%$ of world population consumes GMF and almost 22 million acres are cultivated with transgenic species in the world. Particularly, the analysis related to GMF consumed by the Brazilian population is important due to an increase in its consumption. Considering the increasing demand of GMF and the new developments related to its world production, in the beginning of the 90's the Organization for Economic Cooperation and Development [1] established the concept of substantial equivalence $[2,3]$ to be used as a guide for safe evaluation of GMF. Since then, this guide has been implemented by the Food and Agriculture Organization [3-5], together with many other regulatory agencies in several countries, including the European Commission. The purpose of this study is to check the elemental composition of food containing genetically modified ingredients as well as soybeans cultivated with regular and GMS to perform a comparative analyses, allowing to verify if there are significant modifications in their elemental composition.

\section{EXPERIMENTAL PROCEDURE}

To perform these measurements several brands of potato chips made with conventional and genetically modified potatoes, which are consumed by the local population, were bought in supermarkets at São Paulo city while the soybeans were obtained from plantation where regular and GMS are cultivated. All analyses were performed by mixing and homogenizing each sample obtaining appropriate granules. The ANAA analyses was performed in the IEA Reactor at IPEN facility while the PIXE analysis was performed in the LAMFI (Ion Beam Material Analysis Laboratory) at USP facility.

To identify and determine the element's concentration of elements present in the samples, by using ANAA technique, approximately 50mg of samples were weighed and sealed in the polyethylene bags. The samples were irradiated in the IEA-R1 nuclear reactor at IPEN, by a thermal neutron flux of $5 \times 10^{11} \mathrm{n} / \mathrm{cm}^{2}$ s during 5 minutes, using a pneumatic system, in order to identify short half life isotopes. For the analyses of the long half life isotopes the samples were irradiated for 3 hours in the central core in a flux of $10^{12} \mathrm{n} / \mathrm{cm}^{2} \mathrm{~s}$. The neutron flux was measured with the Cadmium Ratio Technique [6] and the samples were analyzed with HPGe gamma-spectrometer with high resolution Ge detector (FWHM $\leq 1.87 \mathrm{keV}$ at 1.32 $\mathrm{MeV}$ of ${ }^{60} \mathrm{Co}$ ) mounted inside a lead shield hood in order to reduce the background radiation. The detector was operated with 671 ORTEC amplifier, in pile-up rejection mode to reduce the secondary detection effects, besides samples with low activity were produced $(\leq 1 \mu \mathrm{Ci})$ to minimize mainly the Compton scattering. The concentration value of each element were performed using computer code [7]. Typical gammaray spectrum obtained by ANAA are shown in figures 1 and 2. All the analyses were performed with the correction of the background contribution. An example of the soybeans spectrum and the corresponding background contamination in the energy region of $\mathrm{Fe}$ and $\mathrm{Ni}$ is shown in figure 3.

In the analysis performed by PIXE technique [8] the measurements were performed at the LAMFI using a $2.4 \mathrm{MeV}$ proton beam to generate characteristic X-rays of the samples. The powdered samples $(10 \%)$ were mixed with a powdered of Boric Acid $\left(\mathrm{HBO}_{3}\right)(90 \%)$ and compressed (4 tons) into pellets of approximately $1 \mathrm{~cm}$ diameter and $3 \mathrm{~mm}$ thick and $300 \mathrm{mg}$. Typical beam currents used were about a few nA to reduce dead time and pile-up. The acquisition time was 1200 seconds for 


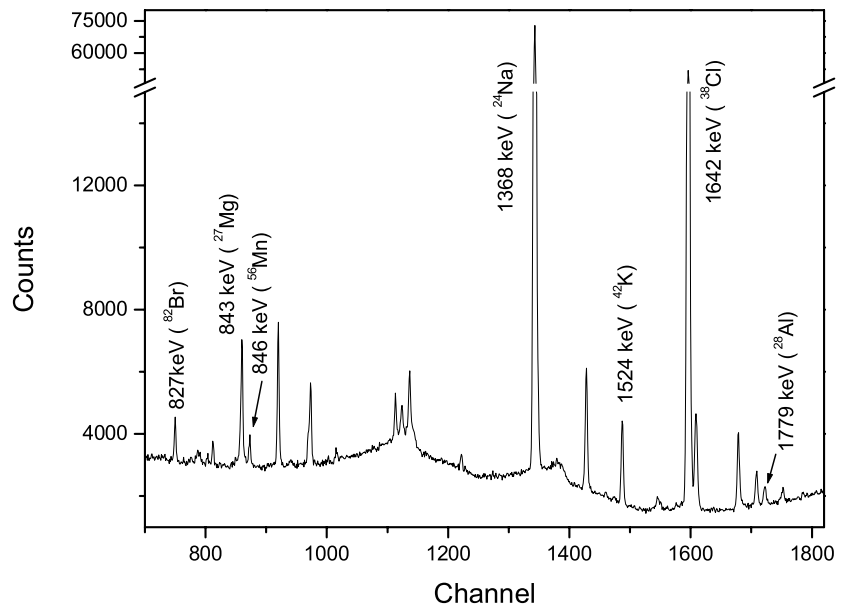

FIG. 1: Partial $\gamma$-ray spectrum of potatoes chips GM for short time irradiation (peaks without energy indication are natural background, time counting 2 hour).

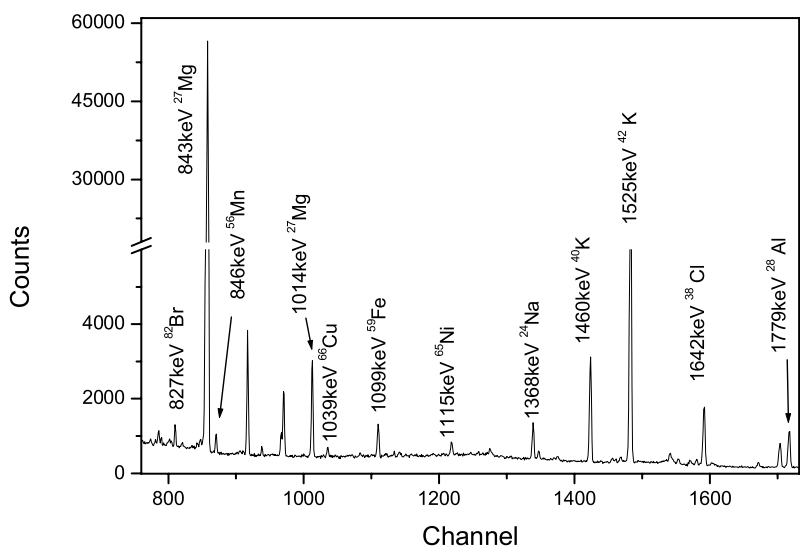

FIG. 2: Partial $\gamma$-ray spectrum of soybeans cultivated in the conventional way for short time irradiation (peaks without energy indication are natural background, time counting 2 hour).

each sample. The X-rays were monitored with a $\mathrm{Si}(\mathrm{Li})$ detector (FWHM resolution of about $145 \mathrm{eV} @ \mathrm{MnK}_{\alpha}$ ) located at an angle of $135^{\circ}$ with respect to the incident beam. A plain thick Mylar absorber $(30 \mu \mathrm{m})$ was used to avoid the detection of back-scattering protons, and a "funny filter" made of a $300 \mu \mathrm{m}$ thick Mylar with $0.1 \mathrm{~mm}$ hole was used to equalize the detection yield and reduce low energy X-rays pile up. The Xray spectra were analyzed using the AXIL analysis software [9]. To determine the concentration of a thick target sample we used a matrix standardization in which the powdered sample is diluted to a few percent $(10 \%)$ in a known matrix made of "light" elements (e.g. Boric Acid). At low concentrations, the energy loss and X-ray absorption coefficients in the matrix can be kept almost unchanged. At the same time, the tt-PIXE yields can be calculated by simply applying a thick target correction factor to the already known thin target PIXE yields. The thick target correction factors were obtained with

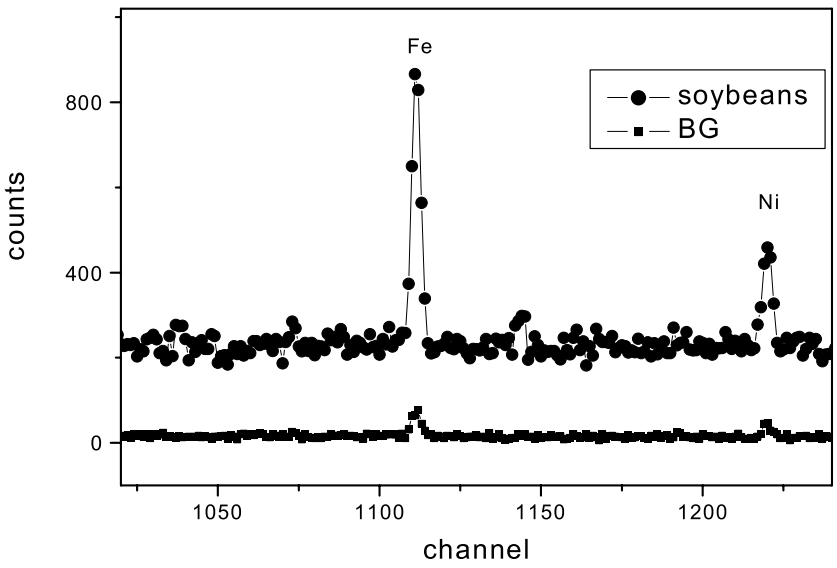

FIG. 3: Partial $\gamma$-ray spectrum of soybeans compared with the background (time counting 30 minutes).

a new computer program CLARA [10] which evaluates the integral of thick target. The corrections factors were calculated for boric acid $\left(\mathrm{HBO}_{3} \mathrm{H}_{2} \mathrm{O}\right)$ matrix which allow determine the elemental concentration (in $\mu \mathrm{gg}^{-1}$ ) for these thick samples.Typical X-ray spectrum are show in figures 4 and 5.

\section{RESULTS AND DISCUSSION}

Four conventional and genetically modified brands of potato chips samples were investigated. To illustrate the results related to potatoes chips (regular and GMF) one brand of each one are presented in Table I. Related to the soybeans seeds the analyses were performed in four soybeans regular seeds and in three GMS. To illustrate the results one of each species are shown in Table II.

According to these Tables the results of ANAA were compatible with PIXE measurements. The elements $\mathrm{Br}, \mathrm{Ca}, \mathrm{Cl}$, $\mathrm{Cr}, \mathrm{Cu}, \mathrm{Fe}, \mathrm{Mn}, \mathrm{Fe}, \mathrm{K}, \mathrm{Ni}$ and $\mathrm{Zn}$ were identified and quantified by both techniques and show compatible concentration values. The elements $\mathrm{Mg}, \mathrm{Na}, \mathrm{S}$ and $\mathrm{P}$ were also identified but, $\mathrm{P}, \mathrm{S}$ and $\mathrm{Rb}$ could only be determined by PIXE, while $\mathrm{Mg}$ and $\mathrm{Na}$ were measured only by ANAA. Althought Al has been identified by ANAA, using the ${ }^{27} \mathrm{Al}(\mathrm{n}, \gamma)^{28} \mathrm{Al}$ reaction, its concentration could not be determined because of the Phosphor present in the samples (identified by PIXE) could also produces $\mathrm{Al}$ by the ${ }^{31} \mathrm{P}(\mathrm{n}, \alpha)^{28} \mathrm{Al}$ reaction when the samples are submitted to neutron irradiation. The elements $\mathrm{Al}, \mathrm{Mg}$ and $\mathrm{Na}$ were not measured by PIXE due to the absorption of X-rays in the detector. Relate to the $\mathrm{S}$ and $\mathrm{Rb}$ quantification, although they have been activated with neutron but they were not calculated by ANAA due a poor counting statistics, but they could be obtained by PIXE. 


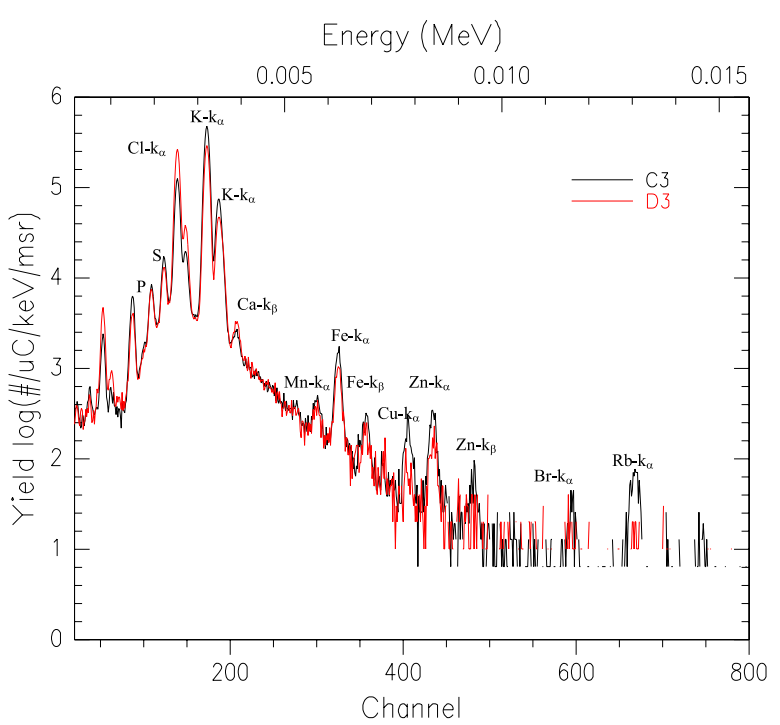

FIG. 4: Typical $\mathrm{X}$-ray spectrum of potatoes chips where $\mathrm{C} 3$ is regular sample and D3 is GM sample.

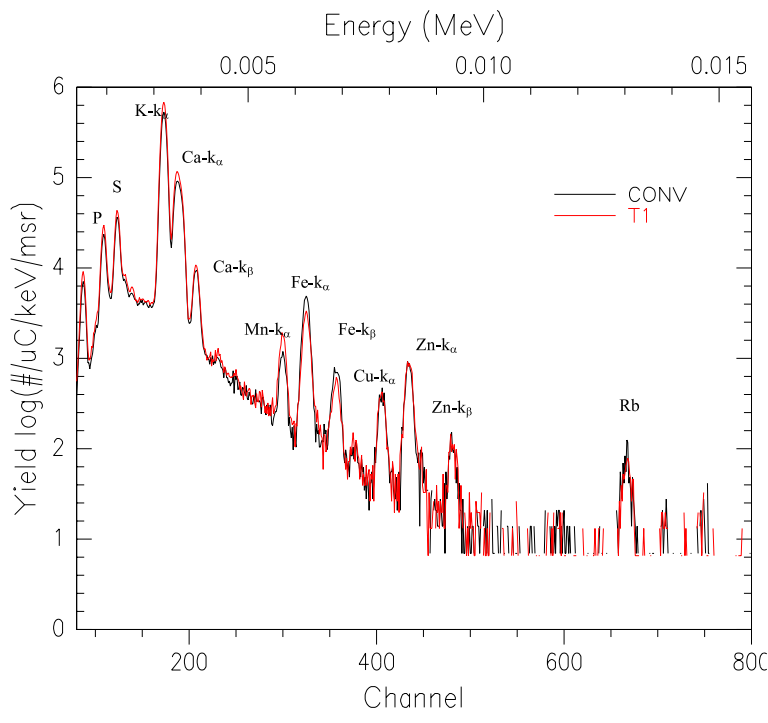

FIG. 5: Typical X-ray spectrum soybeans cultivated with regular (CONV) and GM (T1) seeds.

\section{CONCLUSION}

This experiment allowed the identification of several elements in some conventional and genetically modified products, available commercially, by using Absolute Neutron Activation Analysis (ANAA) and Particle Induced X-Ray Emission (PIXE) techniques. The results show the same elemental composition for all food samples $(\mathrm{Br}, \mathrm{Ca}, \mathrm{Cl}, \mathrm{Cr}, \mathrm{Fe}, \mathrm{K}, \mathrm{Mg}$, $\mathrm{Mn}, \mathrm{Na}, \mathrm{Ni}, \mathrm{P}, \mathrm{Rb}, \mathrm{S}$ and $\mathrm{Zn}$ ) but the comparative analysis suggested that products genetically modified have higher concentration values for the majority of the elements $(\mathrm{Br}, \mathrm{Ca}, \mathrm{Cl}$, $\mathrm{Cr}, \mathrm{Mn}, \mathrm{K}, \mathrm{P}, \mathrm{S}$ and $\mathrm{Zn})$ and for the other are constant $(\mathrm{Cu}$, $\mathrm{Fe}, \mathrm{Mg}, \mathrm{Rb}$ and $\mathrm{Na}$ ) when the comparison is performed with the seeds (soybeans) where no industrial process is involved.

\begin{tabular}{|c|c|c|c|c|}
\hline \multirow[b]{2}{*}{ Element } & PIXE & ANAA & PIXE & ANAA \\
\hline & \multicolumn{2}{|c|}{$\begin{array}{l}\text { Regular } \\
\mu \mathrm{gg}^{-1}\end{array}$} & \multicolumn{2}{|c|}{$\begin{array}{c}\text { GMF } \\
\mu g^{-1}\end{array}$} \\
\hline $\mathrm{P}$ & 955(39) & nd & $1097(222)$ & nd \\
\hline $\mathrm{S}$ & $2159(32)$ & nd & $2039(71)$ & nd \\
\hline $\mathrm{Cl}$ & $4229(37)$ & $3920(10)$ & $6648(79)$ & $6639(122)$ \\
\hline K & $12112(84)$ & $11921(257)$ & $6172(55)$ & $7702(26)$ \\
\hline $\mathrm{Ca}$ & $104(5)$ & $100(14)$ & 192(13) & 221(31) \\
\hline $\mathrm{Cr}$ & $7.6(9)$ & $8.1(6)$ & $10.5(20)$ & $9.8(7)$ \\
\hline $\mathrm{Mn}$ & $7.4(8)$ & $6.9(7)$ & $4.5(16)$ & $5.3(12)$ \\
\hline $\mathrm{Fe}$ & $60.5(12)$ & $66.0(27)$ & $73.7(26)$ & $80.0(41)$ \\
\hline $\mathrm{Ni}$ & $2.5(6)$ & $3.1(2)$ & $2.2(11)$ & $1.9(2)$ \\
\hline $\mathrm{Al}$ & no & nd & no & nd \\
\hline $\mathrm{Mg}$ & no & $11.6(9)$ & no & 7.1(7) \\
\hline $\mathrm{Na}$ & no & $32100(18)$ & no & $22900(22)$ \\
\hline $\mathrm{Cu}$ & $5.6(7)$ & $6.5(4)$ & $1.3(12)$ & $1.5(1)$ \\
\hline $\mathrm{Zn}$ & 17.1(9) & $17.3(14)$ & $2.4(13)$ & $3.0(2)$ \\
\hline $\mathrm{Br}$ & $12.3(31)$ & 13.1(10) & nd & $14.8(6)$ \\
\hline $\mathrm{Rb}$ & $20.7(52)$ & no & no & no \\
\hline
\end{tabular}

no: element not observed

nd: element observed but not determined

TABLE I: The element's concentration in foodstuffs (potato chips) made with regular and genetically modified potatoes obtained by PIXE and ANAA.

\begin{tabular}{c|c|c|c|c}
\multirow{2}{*}{ Element } & PIXE & ANAA & PIXE & ANAA \\
\cline { 2 - 5 } & \multicolumn{2}{|c|}{ Regular $^{-1}$} & \multicolumn{2}{c}{ GMS } \\
& \multicolumn{2}{|c|}{$\mu g^{-1}$} \\
$\mathrm{P}$ & $1672(328)$ & nd & $5139(379)$ & nd \\
$\mathrm{S}$ & $2109(141)$ & nd & $4462(152)$ & nd \\
$\mathrm{Cl}$ & $168(74)$ & $142(11)$ & $649(68)$ & $639(22)$ \\
$\mathrm{K}$ & $8557(101)$ & $7810(274)$ & $19447(178)$ & $17994(341)$ \\
$\mathrm{Ca}$ & $736(30)$ & $681(81)$ & $1113(35)$ & $1021(134)$ \\
$\mathrm{Cr}$ & $6.6(36)$ & $7.8(7)$ & $11.2(36)$ & $10.8(7)$ \\
$\mathrm{Mn}$ & $16.4(34)$ & $14.2(5)$ & $32.9(38)$ & $27.6(28)$ \\
$\mathrm{Fe}$ & $106.3(55)$ & $99.6(55)$ & $102.4(52)$ & $98.7(41)$ \\
$\mathrm{Ni}$ & $9.8(25)$ & $8.5(6)$ & $5.2(21)$ & $4.9(4)$ \\
$\mathrm{Al}$ & no & nd & no & nd \\
$\mathrm{Mg}$ & no & $5.6(5)$ & no & $4.5(4)$ \\
$\mathrm{Na}$ & no & $580(17)$ & no & $571(15)$ \\
$\mathrm{Cu}$ & $7.4(28)$ & $8.4(8)$ & $7.0(26)$ & $5.5(5)$ \\
$\mathrm{Zn}$ & $10.8(34)$ & $12.4(14)$ & $38.8(49)$ & $32.7(22)$ \\
$\mathrm{Br}$ & $1.16(17)$ & $1.01(10)$ & $2.01(53)$ & $1.68(17)$ \\
$\mathrm{Rb}$ & $12.9(5)$ & no & $15.4(14)$ & nd \\
\hline
\end{tabular}

nd: element observed but not determined

TABLE II: The Concentration of the elements in soybeans cultivated of regular and with GMS.

Only for Ni a low concentration was measured. Relate to industrialized food (potatoes chips), which involves addition of different foodstuffs, according to the brand (such as, sugar, salt, acidulant, chemical baking substances, for example), the results are not conclusive but, suggest that, those made with ingredients genetically modified the concentration values diminished for most of the elements, mainly for $\mathrm{Cu}, \mathrm{K}$ and $\mathrm{Zn}$. Finally, the present results show that these analysis could be extend to other kind of seeds (regular and GM) for more nutri- 
tional information considering that GMS show high concentration values, mainly in the majority elements.

\section{Acknowledgments}

The authors thank to FAPESP and CNPq for financial support.

[1] Tech. Rep., Organisation for Economic Co-operation and Development - OECD, Paris (2002), available in http://www.oecd.org/dataoecd/57/3/1946129.pdf.

[2] Application of the principles of substancial equivalence to the safety evaluation of food and food components from plants derived by modern biotechnology, Food and Agriculture Organization of the United Nations/World Health Organization (FAO/WHO) (Report of a WHO - Workshop (WHO/FNU/FOS/95.1), Geneva, 1995).

[3] Food and A. O. of the United Nations/World Health Organization (FAO/WHO), report of a Joint FAO/WHO Expert Consultation on Food Derived from Biotechnology, Geneva (2000), available in http://www.euro.who.int/document/fos/biotechrep72000.pdf.

[4] Biotechnology and food safety. Report of a Joint FAO/WHO Consultation, (FAO Food Nutrition Paper, 61, 31 p.) (Food and Agriculture Organization of the United Nations/World Health
Organization (FAO/WHO), Rome, 1996).

[5] Food and A. O. of the United Nations/World Health Organization (FAO/WHO), Tech. Rep., Yokohama, Japan (2002), available in ftp://ftp.fao.org/codex/Alinorm03/al03_34e.pdf.

[6] U. D. Bitelli, Master's thesis, Instituto de Pesquisas Energéticas e Nucleares - IPEN/SP, Brazil (1988).

[7] J. A. G. Medeiros (2003), Private Communication, Laboratório de Estrutura Nuclear - Instituto de Pesquisas Energéticas e Nucleares - LEN/IPEN.

[8] S. A. E. Johansson and J. L. Campbell, PIXE: A novel technique for elemental analysis (John Wiley\&Sons, Inc., 1988).

[9] P. V. Espen, H. Nullens, and F. Adams, Nucl. Instr.and Meth. 145, 579 (1977)

[10] J. Aburaya, M. H. Tabacniks, M. D. L. Barbosa, N. Added, M. A. Rizzutto, and M. D. L. Barbosa, Submitted to Nucl. Instr.and Meth. (2004). 